\title{
Metabolic alteration of urinary steroids in pre- and post-menopausal women, and men with papillary thyroid carcinoma
}

\author{
Man Ho Choi ${ }^{1}$, Ju-Yeon Moon', Sung-Hee Cho', Bong Chul Chung ${ }^{1 *}$ and Eun Jig Lee ${ }^{2}$
}

\begin{abstract}
Background: To evaluate the metabolic changes in urinary steroids in pre- and post-menopausal women and men with papillary thyroid carcinoma (PTC).

Methods: Quantitative steroid profiling combined with gas chromatography-mass spectrometry was used to measure the urinary concentrations of 84 steroids in both pre- $(n=21$, age: $36.95 \pm 7.19 \mathrm{yr})$ and post-menopausal female ( $n=19$, age: $52.79 \pm 7.66 \mathrm{yr})$, and male $(n=16$, age: $41.88 \pm 8.48 \mathrm{yr})$ patients with PTC. After comparing the quantitative data of the patients with their corresponding controls (pre-menopause women: $\mathrm{n}=24$, age: 33.21 $\pm 10.48 \mathrm{yr}$, post-menopause women: $\mathrm{n}=16$, age: $49.67 \pm 8.94 \mathrm{yr}$, male: $n=20$, age: $42.75 \pm 4.22 \mathrm{yr}$ ), the levels of steroids in the patients were normalized to the mean concentration of the controls to exclude gender and menopausal variations.
\end{abstract}

Results: Many urinary steroids were up-regulated in all PTC patients compared to the controls. Among them, the levels of three active androgens, androstenedione, androstenediol and 16 $\alpha$-hydroxy DHEA, were significantly higher in the pre-menopausal women and men with PTC. The corticoid levels were increased slightly in the PTC men, while progestins were not altered in the post-menopausal PTC women. Estrogens were up-regulated in all PTC patients but 2-hydroxyestrone and 2-hydroxy-17ß-estradiol were remarkably changed in both pre-menopausal women and men with PTC. For both menopausal and gender differences, the 2-hydroxylation, 4-hydroxylation, 2methoxylation, and 4-methoxylation of estrogens and 16 $\alpha$-hydroxylation of DHEA were differentiated between preand post-menopausal PTC women $(P<0.001)$. In particular, the metabolic ratio of 2-hydroxyestrone to 2-hydroxy$17 \beta$-estradiol, which could reveal the enzyme activity of $17 \beta$-hydroxysteroid dehydrogenase, showed gender differences in PTC patients $\left(P<1 \times 10^{-7}\right)$.

Conclusions: These results are expected be helpful for better understanding the pathogenic differences in PTC according to gender and menopausal conditions.

Keywords: Steroids, Thyroid cancer, Menopause, Gender difference, GC-MS

\section{Background}

Papillary thyroid carcinoma (PTC) is the commonest of all thyroid carcinomas and is well-differentiated. The incidence of PTC is three times higher in women than men $[1,2]$ but this gender difference decreases after menopause [3]. The gender differences and menopausal conditions in the incidence of PTC suggest that the

\footnotetext{
* Correspondence: bcc0319@kist.re.kr

'Future Convergence Research Division, Korea Institute of Science and Technology, Seoul 136-791, Korea

Full list of author information is available at the end of the article
}

pathogenesis and development of PTC might be affected by sex steroids, particularly androgens and estrogens [3-11].

The biological activity of estrogens is differentiated by an interaction with both estrogen receptors $\alpha$ and $\beta$ (ER $\alpha$ and $E R \beta)$. Especially, the level of $E R \alpha$ is higher in PTC cells than other thyroid carcinoma cells and normal cells [12]. In addition, the level of ER $\alpha$ is higher in pre-menopausal women than in post-menopausal women and men with PTC [7]. The androgen receptor (AR), which mediates the biological activity of

\section{Biomed Central}


androgens, can be identified in human thyroid cells [13-16]. The levels of AR in thyroid cells are higher in men than in women, and higher in PTC cells than in normal cells [14-16].

Although sex steroids including estrogens and androgens might be associated with both the growth and progression of PTC, the changes in steroids along with gender differences and menopause in PTC have not been well defined. No data is available on the metabolic alteration of steroid profiling between pre- and postmenopausal women, and men with PTC. Therefore, in this study, 84 steroids (including 25 androgens, 17 estrogens, 23 corticoids, 14 progestins, and 5 sterols) in urine samples obtained from pre- and post-menopausal women, and men with PTC were evaluated against the corresponding control groups matched for gender and menopausal condition using gas chromatography-mass spectrometry (GC-MS)-based steroid signatures [17]. Firstly, the urinary levels of steroids in the PTC patients and their controls in the three groups (pre- and postmenopausal women and men) were measured and significance in the individual groups was evaluated using a Student's $t$-test. Secondly, the steroid levels in each patient group were normalized to those of the corresponding controls to exclude the nature of menopausal and gender differences. The change in normalized steroids profiling between the three groups was evaluated by one-way variance analysis (one-way ANOVA). Finally, the metabolic patterns of steroids in the three groups were interpreted by partial least-squares-discrimination analysis (PLS-DA), and examined by ANOVA.

\section{Methods}

\section{Subjects and sample-collection}

Urine samples were collected from pre-menopausal women ( $\mathrm{n}=21$, age: $36.95 \pm 7.19$ yr, BMI: $23.72 \pm 4.69$ $\left.\mathrm{kg} / \mathrm{m}^{2}\right)$, post-menopausal women $(\mathrm{n}=19$, age: $52.79 \pm$ $\left.7.66 \mathrm{yr}, \mathrm{BMI}: 24.46 \pm 2.76 \mathrm{~kg} / \mathrm{m}^{2}\right)$ and men $(\mathrm{n}=16$, age: $41.88 \pm 8.48$ yr, BMI: $25.52 \pm 3.31 \mathrm{~kg} / \mathrm{m}^{2}$ ) with PTC as well as from healthy subjects as the controls for the premenopausal women ( $\mathrm{n}=24$, age: $33.21 \pm 10.48 \mathrm{yr}, \mathrm{BMI}$ : $\left.23.52 \pm 3.94 \mathrm{~kg} / \mathrm{m}^{2}\right)$, post-menopausal women $(\mathrm{n}=16$, age: $\left.49.67 \pm 8.94 \mathrm{yr}, \mathrm{BMI}: 23.02 \pm 3.38 \mathrm{~kg} / \mathrm{m}^{2}\right)$ and men ( $\mathrm{n}=20$, age: $42.75 \pm 4.22 \mathrm{yr}, \mathrm{BMI}: 24.58 \pm 2.49 \mathrm{~kg} / \mathrm{m}^{2}$ ) at the Severance Hospital (Seoul, Korea). All study subjects underwent the same diagnostic procedures, i.e., ultrasound and fine needle aspiration (FNA) as detailed by the American Joint Committee on Cancer staging. Patients with a history of cancer of the cervix, breast, endometrium, or head and neck, and respiratory papillomatosis as well as the post-menopausal women, who have received the estrogen replacement therapy, were excluded. The PTC not invaded the adjacent tissues or showed no spread to nearby lymph nodes. The healthy gender- and age-matched controls had no evidences of benign or malignant thyroid diseases. The first morning urine samples were collected after fasting for at least 12 hours and the patient samples were taken before thyroidectomy. All subjects showed normal thyroid function (T3: $104.11 \pm 19.1 \mathrm{ng} / \mathrm{dL}, \mathrm{T} 4: 11.16 \pm 2.56 \mu \mathrm{g} / \mathrm{dL}$, TSH: $1.02 \pm 0.31 \mu \mathrm{IU} / \mathrm{mL}$ ) and were not treated with or exposed to any drugs including the contraceptive. The experimental protocol (4-2009-0424) was approved by the IRB Committee of the Human Research Protection Center at the Severance Hospital and an informed consent was signed by all subjects. The levels of urinary steroids were calibrated by the creatinine values using Jaffé's method [18].

\section{Chemicals and materials}

The reference standards of the 84 steroids examined in this study (Table 1) were obtained from Sigma (St. Louis, MO), Steraloids (Newport, RI), and NARL (Pumble, Australia). The internal standards, $16,16,17-d_{3}$-testosterone and methyltestosterone for 25 androgens, $2,4,16,16-d_{4}$-estradiol for 17 estrogens, 9,11,12,12- $d_{4}$ cortisol for 23 corticoids, 2,2,4,6,6,17 $\alpha, 21,21,21-d_{9}$-progesterone and $2,2,4,6,6,21,21,21-d_{8}-17 \alpha$-hydroxyprogesterone for 14 progestins, and $2,2,3,4,4,6-d_{6}$-cholesterol for 5 sterols were purchased from NARL and C/D/N isotopes (Pointe-Claire, Quebec, Canada). For solidphase extraction (SPE), an Oasis HLB cartridge $(3 \mathrm{~mL}$, $60 \mathrm{mg}$; Waters, Milford, MA) was preconditioned with 3 $\mathrm{mL}$ of methanol followed by $3 \mathrm{~mL}$ of deionized water. Sodium acetate (reagent grade), acetic acid (glacial, $99.99+\%)$ and L-ascorbic acid (reagent grade) were obtained from Sigma. A solution of $\beta$-glucuronidase was purchased from Roche Diagnostics GmbH (Mannheim, Germany). The trimethylsilylating (TMS) agents, $N$ methyl- $N$-trifluorotrimethylsilyl acetamide (MSTFA), ammonium iodide $\left(\mathrm{NH}_{4} \mathrm{I}\right)$, and dithioerythritol (DTE) were purchased from Sigma. All organic solvents used were of analytical or HPLC grade and were purchased from Burdick \& Jackson (Muskegan, MI). Deionized water was prepared using a Milli-Q purification system (Millipore; Billerica, MA).

\section{Sample preparation}

Quantitative steroid profiling was performed using a previous technique [17]. Briefly, a urine sample $(2 \mathrm{~mL})$ spiked with $20 \mu \mathrm{L}$ of 7 internal standards $\left(d_{3}\right.$-testosterone and $d_{4}$-estradiol: $1 \mu \mathrm{g} / \mathrm{mL}, d_{4}$-cortisol and $d_{8}-17 \alpha$ hydroxyprogesterone: $5 \mu \mathrm{g} / \mathrm{mL}$, methyltestosterone, $d_{9}$ progesterone and $d_{6}$-cholesterol: $10 \mu \mathrm{g} / \mathrm{mL}$ ) was loaded into the Oasis HLB ${ }^{\text {TM }}$ SPE cartridge and washed with 2 $\mathrm{mL}$ water. After elution twice with $2 \mathrm{~mL}$ of methanol, the combined methanol was evaporated under a stream of nitrogen and $1 \mathrm{~mL}$ of $0.2 \mathrm{M}$ acetate buffer ( $\mathrm{pH} 5.2$ ), 
Table 1 Concentrations of urinary steroids in pre-menopausal PTC women and control

\begin{tabular}{|c|c|c|c|}
\hline \multirow[t]{2}{*}{ Steroids } & \multicolumn{2}{|c|}{ Concentration $^{\mathrm{a}}$ (mean \pm SD) } & \multirow{2}{*}{$\frac{P \text {-value }}{\text { Controls : PTC }}$} \\
\hline & $\begin{array}{l}\text { Controls } \\
(\mathrm{n}=24)\end{array}$ & $\begin{array}{c}\text { PTC } \\
(n=21)\end{array}$ & \\
\hline \multicolumn{4}{|l|}{ Androgens } \\
\hline Dihydrotestosterone & $65.79 \pm 47.43$ & $118.67 \pm 61.89$ & $<0.005$ \\
\hline Epidihydrotestosterone & $20.21 \pm 16.70$ & $44.85 \pm 18.85$ & $<0.0007$ \\
\hline Dehydroepiandrosterone & $151.34 \pm 84.40$ & $216.29 \pm 93.00$ & $<0.02$ \\
\hline Testosterone & $64.73 \pm 45.54$ & $116.60 \pm 24.77$ & $<0.03$ \\
\hline Epitestosterone & $82.61 \pm 49.75$ & $109.66 \pm 42.13$ & $N S^{b}$ \\
\hline $5 \alpha$-androstan- $3 \alpha, 17 \beta$-diol & $137.28 \pm 90.96$ & $202.60 \pm 259.73$ & NS \\
\hline $5 \alpha$-androstan-3 $\beta, 17 \beta$-diol & $20.00 \pm 11.75$ & $42.54(1)$ & $N C^{c}$ \\
\hline $5 \beta$-androstan-3 $\alpha, 17 \beta$-diol & $204.52 \pm 149.53$ & $248.07 \pm 336.60$ & NS \\
\hline $5 \beta$-androstan-3 $\alpha, 17 \alpha$-diol & $70.50 \pm 49.49$ & $107.26 \pm 105.68$ & NS \\
\hline 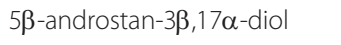 & $5.42 \pm 1.69(4)$ & $6.30 \pm 1.45(3)$ & NC \\
\hline $5 \alpha$-androstan-3 $\beta, 17 \alpha$-diol & $21.17 \pm 14.55$ & $41.20 \pm 28.43$ & NS \\
\hline $5 \alpha$-androstan-3 $\alpha, 17 \alpha$-diol & $33.64 \pm 26.33$ & $53.18 \pm 41.56$ & NS \\
\hline 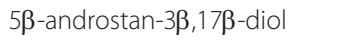 & $8.75(1)$ & $36.84 \pm 53.75(4)$ & NC \\
\hline Androstenedione & $59.17 \pm 50.56$ & $96.93 \pm 39.56$ & $<0.01$ \\
\hline Androstenediol & $51.71 \pm 31.61$ & $96.27 \pm 33.98$ & $<0.0002$ \\
\hline Androsterone & $7826.70 \pm 5459.40$ & $24675.61 \pm 23074.97$ & $<0.004$ \\
\hline Etiocholanolone & $7074.80 \pm 4371.84$ & $21993.33 \pm 14558.44$ & $<0.0002$ \\
\hline $\begin{array}{l}\text { 11-keto-androsterone + } \\
\text { 11-keto-etiocholanolone }\end{array}$ & $439.95 \pm 320.79$ & $2048.15 \pm 1749.63$ & $<0.0005$ \\
\hline $11 \beta$-hydroxyandrosterone & $2413.61 \pm 1411.53$ & $5197.95 \pm 4501.89$ & $<0.01$ \\
\hline $11 \beta$-hydroxyetiocholanolone & $1185.01 \pm 873.09$ & $2598.36 \pm 1740.91$ & $<0.003$ \\
\hline $5 \beta$-dihydrotestosterone & $3.97 \pm 2.92$ & $21.71 \pm 9.26$ & $<0.00008$ \\
\hline 16a-hydroxy-DHEA & $127.76 \pm 67.50$ & $285.48 \pm 147.21$ & $<0.0002$ \\
\hline Epiandrosterone & $33.26 \pm 26.59$ & $49.45 \pm 29.48$ & NS \\
\hline $5 \alpha$-Androstanedione & $36.43 \pm 15.15(11)$ & $59.43 \pm 12.34(4)$ & NC \\
\hline \multicolumn{4}{|l|}{ Estrogens } \\
\hline Estrone & $71.16 \pm 60.17$ & $165.12 \pm 138.61$ & $<0.008$ \\
\hline 17ß-estradiol & $20.78 \pm 19.43$ & $52.64 \pm 42.82$ & $<0.008$ \\
\hline Estriol & $69.12 \pm 55.60$ & $197.03 \pm 403.37$ & NS \\
\hline 2-hydroxyestrone & $298.38 \pm 272.41$ & $126.11 \pm 63.97$ & $<0.007$ \\
\hline 2-hydroxy-17ß-estradiol & $84.88 \pm 60.34$ & $283.06 \pm 247.77$ & $<0.002$ \\
\hline 4-hydroxyestrone & $72.78 \pm 57.37$ & $119.25 \pm 54.27$ & $<0.02$ \\
\hline 4-hydroxy-17/-estradiol & $37.69 \pm 30.34$ & $91.53 \pm 49.54$ & $<0.0003$ \\
\hline 2-methoxyestrone & $53.79 \pm 96.35$ & $94.21 \pm 48.47$ & NS \\
\hline 2-methoxy-17 $\beta$-estradiol & $28.85 \pm 23.85$ & $43.09 \pm 18.79$ & NS \\
\hline 4-methoxyestrone & $36.30 \pm 32.13$ & $61.86 \pm 29.64$ & $<0.04$ \\
\hline 4-methoxy-17 $\beta$-estradiol & $29.38 \pm 19.95$ & $61.79 \pm 37.91$ & $<0.02$ \\
\hline 17-epiestriol & $18.07 \pm 8.07$ & $97.53 \pm 56.54$ & $<0.003$ \\
\hline 16-epiestriol & $37.43 \pm 16.97$ & $83.48 \pm 68.51$ & $<0.02$ \\
\hline $17 \alpha$-estradiol & $2.18 \pm 1.98(2)$ & ND & NC \\
\hline 2-hydroxyestriol & $2.37 \pm 2.74$ & $85.99 \pm 63.04$ & $<0.002$ \\
\hline $\begin{array}{l}\text { 16-keto-17 } \beta \text {-estradiol + } \\
16 \alpha \text {-hydroxyestrone }\end{array}$ & $20.79 \pm 11.75$ & $70.92 \pm 81.33$ & $<0.01$ \\
\hline \multicolumn{4}{|l|}{ Corticoids } \\
\hline Cortisol & $276.27 \pm 348.99$ & $194.98 \pm 121.70$ & NS \\
\hline Allodihydrocortisol & $38.87 \pm 26.40$ & $24.27 \pm 18.96$ & NS \\
\hline Corticosterone & $37.33 \pm 28.36$ & $54.26 \pm 24.03$ & NS \\
\hline Allodihydrocorticosterone & $33.18 \pm 26.19$ & $42.48 \pm 18.15$ & NS \\
\hline Dihydrodeoxycorticosterone & $97.57 \pm 145.03$ & $90.54 \pm 53.46$ & NS \\
\hline
\end{tabular}


Table 1 Concentrations of urinary steroids in pre-menopausal PTC women and control (Continued)

\begin{tabular}{|c|c|c|c|}
\hline 11-deoxycorticosterone & $43.68 \pm 27.30$ & $48.25 \pm 19.29$ & NS \\
\hline 11-deoxycortisol & $59.55 \pm 42.52$ & $53.88 \pm 37.00$ & NS \\
\hline Cortisone & $700.66 \pm 691.13$ & $828.94 \pm 783.61$ & NS \\
\hline Allotetrahydrocortisol & $6987.19 \pm 6000.57$ & $14415.42 \pm 17559.79$ & NS \\
\hline 21-deoxycortisol & $69.17 \pm 45.07$ & $89.61 \pm 80.03$ & NS \\
\hline 11-dehydrocorticosterone & $131.08 \pm 121.05$ & $92.97 \pm 93.87$ & NS \\
\hline Tetrahydrodeoxycortisol & $502.93 \pm 336.31$ & $547.57 \pm 293.54$ & NS \\
\hline Tetrahydrocortisone & $12623.53 \pm 9093.38$ & $14081.85 \pm 11546.70$ & NS \\
\hline Tetrahydrocortisol & $6038.33 \pm 4364.60$ & $10488.74 \pm 9218.05$ & NS \\
\hline Tetrahydrodeoxycorticosterone & $72.07 \pm 90.74$ & $76.89 \pm 88.78$ & NS \\
\hline Tetrahydrocorticosterone & $353.41 \pm 307.84$ & $589.34 \pm 321.77$ & $<0.02$ \\
\hline 11-dehydrotetrahydrocorticosterone & $1403.89 \pm 610.28$ & $992.50 \pm 677.32$ & NS \\
\hline$\alpha$-cortolone & $4989.28 \pm 3076.48$ & $5749.11 \pm 3617.93$ & NS \\
\hline$\beta$-cortolone & $2030.16 \pm 1204.44$ & $2745.91 \pm 1714.17$ & NS \\
\hline 20a-dihydrocortisone & $340.09 \pm 272.98$ & $423.71 \pm 252.98$ & NS \\
\hline$\alpha$-cortol & $921.30 \pm 645.85$ & $884.54 \pm 634.69$ & NS \\
\hline$\beta$-cortol & $2296.04 \pm 1382.42$ & $2602.54 \pm 1638.69$ & NS \\
\hline $20 \alpha$-dihydrocortisol & $209.95 \pm 260.36$ & $130.72 \pm 105.39$ & NS \\
\hline \multicolumn{4}{|l|}{ Progestins } \\
\hline Pregnenolone & $44.36 \pm 33.00$ & $73.78 \pm 32.67$ & $<0.008$ \\
\hline Progesterone & $45.35(1)$ & $194.29(1)$ & NC \\
\hline $5 \beta$-dihydroprogesterone & $7.23 \pm 5.09$ & $7.88(1)$ & NC \\
\hline $5 \alpha$-dihydroprogesterone & $53.83 \pm 26.13$ & $20.36 \pm 25.60$ & $<0.04$ \\
\hline $20 \alpha$-hydroprogesterone & $125.50 \pm 189.43$ & $153.23 \pm 126.74$ & NS \\
\hline Epipregnanolone & $19.10 \pm 17.42$ & $29.50 \pm 12.29$ & NS \\
\hline Pregnanolone & $717.51 \pm 900.30$ & $1305.74 \pm 2701.21$ & NS \\
\hline Allopregnanolone & $198.24 \pm 255.64$ & $188.66 \pm 240.25$ & NS \\
\hline Isopregnanolone & $33.41 \pm 13.44$ & $73.87 \pm 50.59$ & $<0.02$ \\
\hline Pregnanediol & $7025.27 \pm 8837.04$ & $14031.18 \pm 31235.57$ & NS \\
\hline Pregnanetriol & $2874.08 \pm 1477.34$ & $5021.37 \pm 4085.30$ & $<0.04$ \\
\hline $17 \alpha$-hydroxypregnenolone & $57.89 \pm 42.96$ & $87.99 \pm 40.07$ & $<0.03$ \\
\hline $17 \alpha$-hydroxyprogesterone & $53.61 \pm 43.13(6)$ & $97.95 \pm 63.76(2)$ & NC \\
\hline $11 \beta$-hydroxyprogesterone & $938.19 \pm 726.72$ & $1557.51 \pm 1150.75$ & $<0.05$ \\
\hline \multicolumn{4}{|l|}{ Sterols } \\
\hline Cholesterol & $4601.20 \pm 9878.96$ & $7633.19 \pm 8383.76$ & NS \\
\hline Desmosterol & $167.78 \pm 64.99$ & $327.76 \pm 127.00$ & NS \\
\hline Lanosterol & $76.86 \pm 82.14$ & $78.06(1)$ & NC \\
\hline $20 \alpha$-hydroxycholesterol & $59.65 \pm 52.14$ & $93.08 \pm 24.37$ & NS \\
\hline 24S-hydroxycholesterol & $53.36 \pm 35.45$ & $66.87 \pm 30.67$ & NS \\
\hline
\end{tabular}

The number in the parentheses is the number of subject detected corresponding steroid.

${ }^{a}$ Concentrations are expressed as $\mathrm{ng} / \mathrm{g}$ of creatinine (mean $\pm \mathrm{SD}$ ).

${ }^{\mathrm{b}} \mathrm{NS}$, not significant.

${ }^{\mathrm{C}} \mathrm{NC}$, not comparable.

$100 \mu \mathrm{L}$ of $0.2 \% \mathrm{~L}$-ascorbic acid, and $50 \mu \mathrm{L}$ of $\beta$-glucuronidase were then added. After incubation at $55^{\circ} \mathrm{C}$ for 3 $\mathrm{h}$, the solution was extracted twice with $2.5 \mathrm{~mL}$ of ethyl acetate: $n$-hexane $(2: 3, \mathrm{v} / \mathrm{v})$. The combined organic solvents were evaporated using a $\mathrm{N}_{2}$ evaporator at $40^{\circ} \mathrm{C}$ and dried further in a vacuum desiccator over $\mathrm{P}_{2} \mathrm{O}_{5}$ $\mathrm{KOH}$ for at least $30 \mathrm{~min}$. Finally, the dried residue was derivatized with MSTFA/ $\mathrm{NH}_{4} \mathrm{I} / \mathrm{DTE}(40 \mu \mathrm{L} ; 500: 4: 2$, v/ $\mathrm{w} / \mathrm{w}$ ) at $60^{\circ} \mathrm{C}$ for $20 \mathrm{~min}$, and $2 \mu \mathrm{L}$ of the resulting mixture was subjected to GC-MS in selected-ion monitoring (SIM) mode.

\section{Instrumental conditions}

GC-MS was performed using an Agilent 6890 Plus gas chromatograph interfaced with a single-quadrupole Agilent $5975 \mathrm{MSD}$ at an electron energy of $70 \mathrm{eV}$ and ion source temperature of $230^{\circ} \mathrm{C}$. Each sample $(2 \mu \mathrm{L})$ was injected in split mode $(10: 1)$ at $280^{\circ} \mathrm{C}$ and separated 
through an Ultra- 1 capillary column $(25 \mathrm{~m} \times 0.2 \mathrm{~mm}$ i. d., $0.33 \mu \mathrm{m}$ film thickness; Agilent Technologies; Palo Alto, CA). The GC oven temperature was initially set at $215^{\circ} \mathrm{C}$, then ramped to $260^{\circ} \mathrm{C}$ at $1^{\circ} \mathrm{C} / \mathrm{min}$, and finally increased to $320^{\circ} \mathrm{C}$ at $15^{\circ} \mathrm{C} / \mathrm{min}$ and held for $1 \mathrm{~min}$. The carrier gas was helium at a column head pressure of $210.3 \mathrm{kPa}$ (column flow: $1.0 \mathrm{~mL} / \mathrm{min}$ at oven temperature of $215^{\circ} \mathrm{C}$ ). For quantitative analysis, the characteristic ions of each steroid were determined as their TMS derivatives. Peak identifications were achieved by comparing the retention times and matching the height ratios of the characteristic ions [17].

\section{Statistical analysis}

The levels of urinary steroids are reported as the mean \pm SD. The significance of these variables obtained from the controls and PTC groups was examined using a Student's $t$-test. The variables in PTC were normalized to the mean of the corresponding controls, and significance of the normalized three groups was also evaluated by one-way variance analysis (one-way ANOVA). A $P$-value $<0.01$ was considered significant. Partial least squaresdiscrimination analysis (PLS-DA) with multivariate data analysis software SIMCA-P (version 11.0, Umetrics Inc., Sweden) was used for clustering the study groups.

\section{Multivariate data analysis}

The processed data was stored in either Excel spreadsheets or Comma Separated Values (CSV) formatted files and then imported into SIMCA software. The urinary steroid levels were classified by PLS-DA for pre- and post-menopausal female and male PTC patients after normalization. PLS-DA maximizes the covariance between the predicting data set, which is $X$ of the numerical value of the targeted steroids, and $\mathrm{Y}$ of the class assignment.

The fraction of the variation in the $\mathrm{Y}$ variables "explained" by the selected components $\left(R^{2} Y\right)$, along with the fraction of the variation of Y's that can be "predicted" by a component according to cross validation $\left(Q^{2} Y\right)$ were calculated to plot and validate the model. After calculating the components for the PLS-DA scatter plot, the significant components were selected according to the rule embedded in SIMCA-P software, whereby $\mathrm{Q}^{2}$ should be larger than zero for more than 100 observations and 0.05 for $\leq 100$ observations. The PLS-DA plots were then displayed as the superposition of the highest two latent variables $(\mathrm{t}[1] / \mathrm{t}[2]$ or $\mathrm{p}[1] / \mathrm{p}[2]$ as $\mathrm{X}-$, Y- axes), such that most of the association with dummy $Y$ variables could be explained by the variations in $X$. In addition, the high coefficient values of $R^{2} Y$ and $Q^{2} Y$ revealed good discrimination. In this study, the urinary steroids were scaled and centered prior to PLSDA. One point in the scatter plot represents the rates of steroid secretion. The metabolic patterns can be interpreted using visual images or the $R^{2} Y$ and $Q^{2} Y$ values.

\section{Results}

Urinary levels of steroids in PTC patients

The urinary levels of 84 steroids in the pre- and postmenopausal women and men with PTC, along with their corresponding controls were profiled quantitatively. Tables 1, 2 and 3 list the concentrations in the three PTC groups and their individual controls. In premenopausal PTC women, all estrogens including estrone $(P<0.008)$, $17 \beta$-estradiol $(P<0.008), 2$-hydroxy- $17 \beta$ estradiol $(P<0.002)$, 4-hydroxy-17 $\beta$-estradiol $(P<$ $0.0003), 17$-epiestriol $(P<0.003), 2$-hydroxyestriol $(P<$ 0.002 ) were increased, whereas 2-hydroxyestrone was significantly decreased $(P<0.007)$. All androgens were also up-regulated in the PTC patients including the most active androgens, dihydrotestosterone $(P<0.005)$, androstenediol $(P<0.0002)$, and $16 \alpha$-hydroxy DHEA $(P$ $<0.0002)$. Progestins tended to be higher in the PTC patients, but the $5 \alpha$-dihydroprogesterone levels were slightly lower $(P<0.04)$. Both corticoids and sterols were not significant (Table 1), whereas lanosterol was detectable in only one patient.

In contrast, the levels of corticosterone $(P<0.02)$, dihydrodeoxycorticosterone $(P<0.02)$, tetrahydrocortisol $(P<0.05)$ and tetrahydrocorticosterone $(P<0.02)$ were slightly higher in the post-menopausal PTC women than in the corresponding controls (Table 2). Most estrogens could be up-regulated in the groups studied but their urinary levels were undetectable in many post-menopausal women in both the patient and control groups. The levels of $5 \beta$-dihydrotestosterone were significantly higher in the patient group $(P<0.00003)$, but this was not clinically meaningful. The other steroids, progestins and sterols were not significant.

In PTC men, the 4-hydroxy-17 $\beta$-estradiol $(P<$ 0.00009), 2 -methoxyestrone $(P<0.006)$ and 4 -methoxyestrone $(P<0.003)$ levels were significantly higher in the patients, whereas 2 -hydroxy-17 $\beta$-estradiol levels were lower $(P<0.00007 ;$ Table 3$)$. In particular, increased levels of 2-hydroxyestrone and decreased levels of 2 -hydroxy-17 $\beta$-estradiol in the patients were reversible with the results obtained from the PTC women. Although the corticoids levels in the pre- and post-menopausal women groups were not associated with PTC, the levels of most corticoids were higher the patients except for allodihydrocortisol (38.21 \pm 28.01 ng/g creatinine for controls; $17.59 \pm 8.64$ for patients, $P$ $<0.005)$. Some active androgens including androstenedione $(P<0.002)$, androstenediol $(P<0.00005)$ and $16 \alpha$-hydroxy-DHEA $(P<0.000005)$ in the patients were associated with PTC. The levels of progestins and sterols were not remarkable. 
Table 2 Concentrations of urinary steroids in post-menopausal PTC women and control

\begin{tabular}{|c|c|c|c|}
\hline \multirow[t]{2}{*}{ Steroids } & \multicolumn{2}{|c|}{ Concentration $^{\mathrm{a}}$ (mean \pm SD) } & \multirow{2}{*}{$\begin{array}{c}P \text {-value } \\
\text { Controls : PTC }\end{array}$} \\
\hline & $\begin{array}{l}\text { Controls } \\
(\mathrm{n}=16)\end{array}$ & $\begin{array}{c}\text { PTC } \\
(n=19)\end{array}$ & \\
\hline \multicolumn{4}{|l|}{ Androgens } \\
\hline Dihydrotestosterone & $71.99 \pm 45.10$ & $91.87 \pm 57.97$ & $N S^{b}$ \\
\hline Epidihydrotestosterone & $38.16 \pm 27.60$ & $32.35 \pm 58.50$ & NS \\
\hline Dehydroepiandrosterone & $165.46 \pm 91.64$ & $194.37 \pm 109.70$ & NS \\
\hline Testosterone & $102.07 \pm 64.62$ & $196.74 \pm 232.37$ & NS \\
\hline Epitestosterone & $92.02 \pm 69.39$ & $91.08 \pm 60.77$ & $N S^{b}$ \\
\hline $5 \alpha$-androstan- $3 \alpha, 17 \beta$-diol & $87.09 \pm 64.60$ & $112.99 \pm 94.87$ & NS \\
\hline 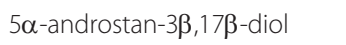 & $4.26(1)$ & $N D^{c}$ & $N C^{d}$ \\
\hline $5 \beta$-androstan-3 $\alpha, 17 \beta$-diol & $99.98 \pm 74.50$ & $109.73 \pm 90.40$ & NS \\
\hline $5 \beta$-androstan-3 $\alpha, 17 \alpha$-diol & $67.53 \pm 62.11$ & $61.33 \pm 68.37$ & NS \\
\hline 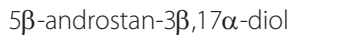 & $14.33 \pm 13.01(2)$ & $9.58 \pm 7.20(4)$ & NC \\
\hline $5 \alpha$-androstan-3$\beta, 17 \alpha$-diol & $22.27 \pm 20.57(2)$ & $34.51 \pm 28.74$ & NC \\
\hline $5 \alpha$-androstan- $3 \alpha, 17 \alpha$-diol & $43.24 \pm 52.23$ & $37.50 \pm 24.00$ & NS \\
\hline 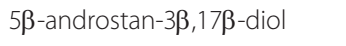 & ND & $18.10(1)$ & NC \\
\hline Androstenedione & $110.21 \pm 88.05$ & $112.78 \pm 59.83$ & NS \\
\hline Androstenediol & $54.27 \pm 26.28$ & $61.30 \pm 13.63$ & NS \\
\hline Androsterone & $4464.11 \pm 1786.06$ & $14974.73 \pm 17229.72$ & $<0.02$ \\
\hline Etiocholanolone & $4850.22 \pm 2075.09$ & $13920.59 \pm 15821.56$ & $<0.03$ \\
\hline $\begin{array}{l}\text { 11-keto-androsterone }+ \\
\text { 11-keto-etiocholanolone }\end{array}$ & $580.33 \pm 297.69$ & $1727.55 \pm 2045.94$ & $<0.03$ \\
\hline $11 \beta$-hydroxyandrosterone & $4499.84 \pm 2455.83$ & $5488.85 \pm 4203.96$ & NS \\
\hline 11 $\beta$-hydroxyetiocholanolone & $1462.44 \pm 1071.41$ & $2629.38 \pm 2439.84$ & NS \\
\hline $5 \beta$-dihydrotestosterone & $4.79 \pm 1.61$ & $21.03 \pm 9.54$ & $<0.00003$ \\
\hline 16 $\alpha$-hydroxy-DHEA & $228.48 \pm 172.71$ & $271.17 \pm 127.46$ & NS \\
\hline Epiandrosterone & $60.19 \pm 61.75$ & $70.25 \pm 35.51$ & NS \\
\hline $5 \alpha$-Androstanedione & $72.20 \pm 83.17$ (4) & $60.13 \pm 24.16(13)$ & NC \\
\hline \multicolumn{4}{|l|}{ Estrogens } \\
\hline Estrone & $163.00 \pm 176.41(6)$ & $63.72 \pm 47.10(17)$ & NC \\
\hline $17 \beta$-estradiol & $14.24 \pm 14.24$ & $21.84 \pm 19.84(7)$ & NC \\
\hline Estriol & $56.96 \pm 65.77(6)$ & $60.11 \pm 57.72(17)$ & NC \\
\hline 2-hydroxyestrone & $306.99 \pm 99.92(5)$ & $50.92 \pm 30.20(18)$ & NC \\
\hline 2-hydroxy-17ß-estradiol & $131.39 \pm 166.91(6)$ & $168.07 \pm 372.40(17)$ & NC \\
\hline 4-hydroxyestrone & $76.21 \pm 15.24(4)$ & $42.27 \pm 49.44(15)$ & NC \\
\hline 4-hydroxy-17ß-estradiol & $33.90 \pm 13.10(4)$ & $44.94 \pm 23.08(16)$ & NC \\
\hline 2-methoxyestrone & $69.67 \pm 77.40(6)$ & $101.47 \pm 68.85(7)$ & NC \\
\hline 2-methoxy-17 $\beta$-estradiol & $24.53 \pm 11.18$ (3) & $60.09 \pm 29.12(7)$ & NC \\
\hline 4-methoxyestrone & $32.32(1)$ & $85.60 \pm 41.64(15)$ & NC \\
\hline 4-methoxy-17 $\beta$-estradiol & $66.69 \pm 75.09$ (4) & $55.39 \pm 11.16(4)$ & NC \\
\hline 17-epiestriol & $254.59(1)$ & $94.42 \pm 44.07$ (8) & NC \\
\hline 16-epiestriol & $74.15 \pm 85.83(6)$ & $119.59 \pm 63.08(6)$ & NC \\
\hline $17 \alpha$-estradiol & ND & ND & NC \\
\hline 2-hydroxyestriol & ND & $90.89 \pm 102.52(5)$ & NC \\
\hline $\begin{array}{l}\text { 16-keto-17 } \beta \text {-estradiol + } \\
16 \alpha \text {-hydroxyestrone }\end{array}$ & $28.01 \pm 33.72(6)$ & $46.10 \pm 24.21$ & NC \\
\hline \multicolumn{4}{|l|}{ Corticoids } \\
\hline Cortisol & $235.02 \pm 205.57$ & $561.28 \pm 345.19$ & NS \\
\hline Allodihydrocortisol & $71.42 \pm 64.96$ & $61.67 \pm 84.03$ & NS \\
\hline Corticosterone & $20.74 \pm 5.63$ & $100.83 \pm 85.62$ & $<0.02$ \\
\hline Allodihydrocorticosterone & $53.16 \pm 46.48$ & $66.19 \pm 38.41$ & NS \\
\hline Dihydrodeoxycorticosterone & $20.41 \pm 15.52$ & $162.62 \pm 155.03$ & $<0.02$ \\
\hline
\end{tabular}


Table 2 Concentrations of urinary steroids in post-menopausal PTC women and control (Continued)

\begin{tabular}{|c|c|c|c|}
\hline 11-deoxycorticosterone & $101.66 \pm 97.56$ & $61.76 \pm 29.06$ & NS \\
\hline 11-deoxycortisol & $101.54 \pm 102.04$ & $45.92 \pm 22.60$ & NS \\
\hline Cortisone & $980.80 \pm 750.48$ & $2205.39 \pm 2667.76$ & NS \\
\hline Allotetrahydrocortisol & $9613.87 \pm 6293.12$ & $17105.92 \pm 16369.40$ & NS \\
\hline 21-deoxycortisol & $86.96 \pm 32.86$ & $97.31 \pm 54.06$ & NS \\
\hline 11-dehydrocorticosterone & $124.14 \pm 75.34$ & $194.61 \pm 298.04$ & NS \\
\hline Tetrahydrodeoxycortisol & $794.79 \pm 305.00$ & $818.38 \pm 581.02$ & NS \\
\hline Tetrahydrocortisone & $17811.52 \pm 12271.25$ & $16114.72 \pm 12222.84$ & NS \\
\hline Tetrahydrocortisol & $8640.16 \pm 4558.83$ & $16040.33 \pm 12750.63$ & $<0.05$ \\
\hline Tetrahydrodeoxycorticosterone & $56.16 \pm 73.09$ & $43.58 \pm 61.64$ & NS \\
\hline Tetrahydrocorticosterone & $389.66 \pm 207.67$ & $780.31 \pm 575.27$ & $<0.02$ \\
\hline 11-dehydrotetrahydrocorticosterone & $877.74 \pm 538.13$ & $1445.62 \pm 1602.49$ & NS \\
\hline$\alpha$-cortolone & $4888.98 \pm 2535.86$ & $29149.71 \pm 97516.67$ & NS \\
\hline$\beta$-cortolone & $2589.95 \pm 927.40$ & $5524.05 \pm 11016.02$ & NS \\
\hline 20a-dihydrocortisone & $375.30 \pm 192.08$ & $1766.88 \pm 5192.38$ & NS \\
\hline$\alpha$-cortol & $944.46 \pm 362.03$ & $5294.32 \pm 17534.68$ & NS \\
\hline$\beta$-cortol & $2299.34 \pm 908.51$ & $8550.42 \pm 23540.39$ & NS \\
\hline $20 \alpha$-dihydrocortisol & $172.51 \pm 127.47$ & $786.04 \pm 2141.06$ & NS \\
\hline \multicolumn{4}{|l|}{ Progestins } \\
\hline Pregnenolone & $66.45 \pm 68.65$ & $108.91 \pm 65.30$ & NS \\
\hline Progesterone & ND & $47.86(1)$ & NC \\
\hline $5 \beta$-dihydroprogesterone & $13.35 \pm 9.78$ & ND & NC \\
\hline $5 \alpha$-dihydroprogesterone & $38.87 \pm 28.09$ (2) & $24.96 \pm 37.35$ & NC \\
\hline $20 \alpha$-hydroprogesterone & $121.40 \pm 105.37(3)$ & $276.33 \pm 450.77$ & NC \\
\hline Epipregnanolone & $63.07 \pm 63.10$ & $37.64 \pm 22.54$ & NS \\
\hline Pregnanolone & $652.71 \pm 1018.03$ & $489.54 \pm 1157.06$ & NS \\
\hline Allopregnanolone & $147.26 \pm 129.01$ & $109.29 \pm 187.61$ & NS \\
\hline Isopregnanolone & $60.44 \pm 5.17(3)$ & $73.12 \pm 43.22$ & NC \\
\hline Pregnanediol & $6959.54 \pm 12541.46$ & $3635.06 \pm 9400.59$ & NS \\
\hline Pregnanetriol & $1559.68 \pm 1314.30$ & $2612.22 \pm 3133.33$ & NS \\
\hline 17 $\alpha$-hydroxypregnenolone & $85.37 \pm 85.75$ & $106.24 \pm 57.67$ & NS \\
\hline $17 \alpha$-hydroxyprogesterone & ND & $133.63 \pm 84.38$ & NC \\
\hline $11 \beta$-hydroxyprogesterone & $1204.77 \pm 516.99$ & $6580.30 \pm 17763.59$ & NS \\
\hline \multicolumn{4}{|l|}{ Sterols } \\
\hline Cholesterol & $5103.58 \pm 3075.92(6)$ & $5002.90 \pm 3033.29$ & NC \\
\hline Desmosterol & $197.65 \pm 67.86(2)$ & ND & NC \\
\hline Lanosterol & $102.03 \pm 125.18$ & $32.83 \pm 20.51$ (3) & NC \\
\hline $20 \alpha$-hydroxycholesterol & ND & $86.56 \pm 4.77(2)$ & NC \\
\hline 24S-hydroxycholesterol & $116.58 \pm 101.37(4)$ & $54.63 \pm 26.17(7)$ & NC \\
\hline
\end{tabular}

The number in the parentheses is the number of subject detected corresponding steroid.

${ }^{a}$ Concentrations are expressed as $\mathrm{ng} / \mathrm{g}$ of creatinine (mean $\pm \mathrm{SD}$ ).

${ }^{\mathrm{b}} \mathrm{NS}$, not significant.

${ }^{\mathrm{C}} \mathrm{ND}$, not detected.

${ }^{\mathrm{d} N C}$, not comparable.

In all cases, androgens were up-regulated in the patient groups compared to the control groups. Among the urinary androgens studied, five androgens (androsterone, etiocholanolone, 11-keto-androsterone, 11-ketoetiocholanolone and 5 $\beta$-DHT), which are abundant steroids in humans, were significantly higher in all patient groups (Tables 1, 2, and 3). Active androgens including androstenedione, androstenediol and 16 $\alpha$-hydroxy
DHEA were significantly higher in the pre-menopausal women and men with PTC, but not in the post-menopausal PTC women. Estrogens were also up-regulated in all patients compared to the controls. In particular, the 2-hydroxyestrone level was lower in the pre-menopausal PTC women $(P<0.007)$ but higher in the PTC men $(P$ $<0.02$ ). In contrast, 2 -hydroxy-17 $\beta$-estradiol was higher in the pre-menopausal PTC women $(P<0.002)$, whereas 
Table 3 Concentrations of urinary steroids in the PTC men and control

\begin{tabular}{|c|c|c|c|}
\hline \multirow[t]{2}{*}{ Steroids } & \multicolumn{2}{|c|}{ Concentration $^{\mathrm{a}}($ mean \pm SD) } & \multirow{2}{*}{$\begin{array}{c}P \text {-value } \\
\text { Controls : PTC }\end{array}$} \\
\hline & $\begin{array}{l}\text { Controls } \\
(\mathrm{n}=20)\end{array}$ & $\begin{array}{c}\text { PTC } \\
(n=16)\end{array}$ & \\
\hline \multicolumn{4}{|l|}{ Androgens } \\
\hline Dihydrotestosterone & $91.39 \pm 62.43$ & $132.14 \pm 92.41$ & $N S^{b}$ \\
\hline Epidihydrotestosterone & $20.74 \pm 16.54$ & $28.45 \pm 14.21$ & NS \\
\hline Dehydroepiandrosterone & $144.93 \pm 58.60$ & $180.74 \pm 85.79$ & NS \\
\hline Testosterone & $101.16 \pm 89.00$ & $271.30 \pm 270.50$ & NS \\
\hline Epitestosterone & $181.57 \pm 93.89$ & $177.67 \pm 111.44$ & NS \\
\hline $5 \alpha$-androstan-3 $\alpha, 17 \beta$-diol & $381.95 \pm 183.28$ & $320.57 \pm 198.42$ & NS \\
\hline $5 \alpha$-androstan-3 $\beta, 17 \beta$-diol & $3.70 \pm 3.66$ & $83.37 \pm 99.92$ & NS \\
\hline $5 \beta$-androstan-3 $\alpha, 17 \beta$-diol & $432.61 \pm 362.77$ & $607.93 \pm 1056.85$ & NS \\
\hline $5 \beta$-androstan- $3 \alpha, 17 \alpha$-diol & $55.09 \pm 46.59$ & $109.91 \pm 153.06$ & NS \\
\hline 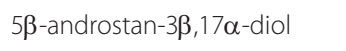 & $N D^{c}$ & $4.92(1)$ & $N C^{d}$ \\
\hline $5 \alpha$-androstan-3 $\beta, 17 \alpha$-diol & $31.72 \pm 39.33$ & $54.92 \pm 80.93$ & NS \\
\hline $5 \alpha$-androstan- $3 \alpha, 17 \alpha$-diol & $31.13 \pm 28.59$ & $40.00 \pm 63.40$ & NS \\
\hline 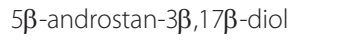 & $2.51(1)$ & ND & NC \\
\hline Androstenedione & $40.66 \pm 21.23$ & $92.10 \pm 51.74$ & $<0.002$ \\
\hline Androstenediol & $28.68 \pm 12.20$ & $82.31 \pm 38.09$ & $<0.00005$ \\
\hline Androsterone & $10087.69 \pm 4603.39$ & $26110.67 \pm 11663.35$ & $<0.00006$ \\
\hline Etiocholanolone & $8256.47 \pm 3997.97$ & $24745.49 \pm 16868.98$ & $<0.002$ \\
\hline $\begin{array}{l}\text { 11-keto-androsterone + } \\
\text { 11-keto-etiocholanolone }\end{array}$ & $531.90 \pm 598.85$ & $1660.94 \pm 1191.92$ & $<0.003$ \\
\hline $11 \beta$-hydroxyandrosterone & $4009.02 \pm 2754.69$ & $7037.26 \pm 4372.55$ & $<0.02$ \\
\hline 11 $\beta$-hydroxyetiocholanolone & $1295.60 \pm 1325.27$ & $2087.71 \pm 1610.32$ & NS \\
\hline $5 \beta$-dihydrotestosterone & $3.01 \pm 1.85$ & $17.67 \pm 20.67$ & $<0.02$ \\
\hline 16a-hydroxy-DHEA & $79.37 \pm 43.01$ & $186.33 \pm 63.29$ & $<0.000005$ \\
\hline Epiandrosterone & $24.21 \pm 10.91$ & $46.90 \pm 33.66$ & $<0.02$ \\
\hline $5 \alpha$-Androstanedione & $11.29(1)$ & $24.39(1)$ & $\mathrm{NC}$ \\
\hline \multicolumn{4}{|l|}{ Estrogens } \\
\hline Estrone & $39.69 \pm 12.89$ & $60.18 \pm 29.20$ & $<0.02$ \\
\hline $17 \beta$-estradiol & $12.91 \pm 12.56$ & $15.05 \pm 10.68$ & NS \\
\hline Estriol & $24.62 \pm 11.84$ & $44.79 \pm 31.46$ & $<0.03$ \\
\hline 2-hydroxyestrone & $50.27 \pm 25.50$ & $91.83 \pm 55.12$ & $<0.02$ \\
\hline 2-hydroxy-17ß-estradiol & $195.56 \pm 113.59$ & $64.98 \pm 38.05$ & $<0.00007$ \\
\hline 4-hydroxyestrone & $51.38 \pm 26.59$ & $59.70 \pm 24.78$ & NS \\
\hline 4-hydroxy-17ß-estradiol & $18.29 \pm 7.63$ & $42.05 \pm 13.14$ & $<0.00009$ \\
\hline 2-methoxyestrone & $22.78 \pm 13.07$ & $42.46 \pm 20.94$ & $<0.006$ \\
\hline 2-methoxy-17 $\beta$-estradiol & $19.41 \pm 9.13$ & $27.37 \pm 14.25$ & NS \\
\hline 4-methoxyestrone & $17.78 \pm 7.24$ & $34.29 \pm 16.50$ & $<0.003$ \\
\hline 4-methoxy-17 $\beta$-estradiol & $19.00 \pm 9.90$ & $28.78 \pm 11.78$ & $<0.03$ \\
\hline 17-epiestriol & $42.81(1)$ & $49.14 \pm 5.76(2)$ & NC \\
\hline 16-epiestriol & $28.28 \pm 19.49$ & $34.70 \pm 16.18$ & NS \\
\hline 17 $\alpha$-estradiol & $0.92(1)$ & ND & NC \\
\hline 2-hydroxyestriol & $0.57 \pm 0.77$ & $40.82 \pm 69.05$ & NS \\
\hline $\begin{array}{l}\text { 16-keto-17ß-estradiol + } \\
16 \alpha \text {-hydroxyestrone }\end{array}$ & $9.99 \pm 4.63$ & $22.93 \pm 10.98$ & $<0.0003$ \\
\hline \multicolumn{4}{|l|}{ Corticoids } \\
\hline Cortisol & $183.91 \pm 160.81$ & $487.21 \pm 482.28$ & $<0.03$ \\
\hline Allodihydrocortisol & $38.21 \pm 28.01$ & $17.59 \pm 8.64$ & $<0.005$ \\
\hline Corticosterone & $33.47 \pm 32.89$ & $56.57 \pm 91.42$ & NS \\
\hline Allodihydrocorticosterone & $22.53 \pm 10.10$ & $29.87 \pm 13.54$ & NS \\
\hline Dihydrodeoxycorticosterone & $32.30 \pm 37.87$ & $134.38 \pm 105.38$ & $<0.02$ \\
\hline
\end{tabular}


Table 3 Concentrations of urinary steroids in the PTC men and control (Continued)

\begin{tabular}{|c|c|c|c|}
\hline 11-deoxycorticosterone & $28.74 \pm 15.27$ & $28.78 \pm 13.55$ & NS \\
\hline 11-deoxycortisol & $37.14 \pm 16.35$ & $32.66 \pm 15.58$ & NS \\
\hline Cortisone & $511.43 \pm 377.83$ & $1580.13 \pm 1320.58$ & $<0.006$ \\
\hline Allotetrahydrocortisol & $9510.49 \pm 4735.51$ & $20666.67 \pm 12334.24$ & $<0.003$ \\
\hline 21-deoxycortisol & $63.27 \pm 29.68$ & $88.63 \pm 45.03$ & NS \\
\hline 11-dehydrocorticosterone & $110.59 \pm 105.33$ & $148.87 \pm 147.64$ & NS \\
\hline Tetrahydrodeoxycortisol & $405.48 \pm 214.37$ & $756.82 \pm 539.85$ & $<0.03$ \\
\hline Tetrahydrocortisone & $11055.45 \pm 5289.49$ & $18809.78 \pm 11894.93$ & $<0.03$ \\
\hline Tetrahydrocortisol & $6091.23 \pm 2812.78$ & $16371.31 \pm 10629.87$ & $<0.002$ \\
\hline Tetrahydrodeoxycorticosterone & $24.76 \pm 15.31$ & $37.50 \pm 24.52$ & NS \\
\hline Tetrahydrocorticosterone & $433.03 \pm 604.84$ & $659.73 \pm 380.95$ & NS \\
\hline 11-dehydrotetrahydrocorticosterone & $993.99 \pm 1013.47$ & $1127.02 \pm 618.49$ & NS \\
\hline$\alpha$-cortolone & $4030.85 \pm 1778.81$ & $6992.04 \pm 3748.34$ & $<0.009$ \\
\hline$\beta$-cortolone & $2284.12 \pm 1041.75$ & $3306.24 \pm 1662.55$ & $<0.05$ \\
\hline 20a-dihydrocortisone & $252.58 \pm 107.63$ & $431.88 \pm 202.66$ & $<0.005$ \\
\hline$\alpha$-cortol & $838.32 \pm 319.86$ & $1180.62 \pm 550.93$ & $<0.04$ \\
\hline$\beta$-cortol & $2181.33 \pm 886.33$ & $3316.76 \pm 1830.36$ & $<0.04$ \\
\hline $20 \alpha$-dihydrocortisol & $87.90 \pm 57.63$ & $188.16 \pm 129.88$ & $<0.01$ \\
\hline \multicolumn{4}{|l|}{ Progestins } \\
\hline Pregnenolone & $27.08 \pm 13.26$ & $41.82 \pm 15.30$ & $<0.02$ \\
\hline Progesterone & $22.47 \pm 11.45(2)$ & $47.85 \pm 10.86(3)$ & NC \\
\hline $5 \beta$-dihydroprogesterone & $7.90 \pm 7.77$ & 11.18 & NS \\
\hline $5 \alpha$-dihydroprogesterone & $24.37 \pm 11.29$ & $28.45 \pm 35.05$ & NS \\
\hline $20 \alpha$-hydroprogesterone & $35.96 \pm 24.53$ & $76.35 \pm 54.00$ & $<0.01$ \\
\hline Epipregnanolone & $13.87 \pm 8.23$ & $16.85 \pm 6.83$ & NS \\
\hline Pregnanolone & $251.57 \pm 121.38$ & $559.35 \pm 835.31$ & NS \\
\hline Allopregnanolone & $55.53 \pm 25.97$ & $92.13 \pm 129.62$ & NS \\
\hline Isopregnanolone & $32.57 \pm 11.39$ & $47.07 \pm 24.81$ & NS \\
\hline Pregnanediol & $1896.17 \pm 1077.27$ & $5669.51 \pm 10408.32$ & NS \\
\hline Pregnanetriol & $2704.00 \pm 1146.97$ & $3975.05 \pm 1957.07$ & $<0.04$ \\
\hline 17 $\alpha$-hydroxypregnenolone & $39.84 \pm 22.13$ & $58.70 \pm 38.95$ & NS \\
\hline $17 \alpha$-hydroxyprogesterone & $15.19(1)$ & $39.82 \pm 19.99$ & NC \\
\hline $11 \beta$-hydroxyprogesterone & $818.94 \pm 373.38$ & $2518.86 \pm 1739.51$ & $<0.002$ \\
\hline \multicolumn{4}{|l|}{ Sterols } \\
\hline Cholesterol & $2028.74 \pm 1781.46$ & $3851.26 \pm 2743.30$ & $<0.04$ \\
\hline Desmosterol & $216.36 \pm 88.55$ & $421.52 \pm 622.80$ & NS \\
\hline Lanosterol & $58.32 \pm 73.89$ & $43.89 \pm 30.30$ & NS \\
\hline $20 \alpha$-hydroxycholesterol & $49.98(1)$ & $85.15(1)$ & NC \\
\hline 24S-hydroxycholesterol & $111.65 \pm 207.00$ & $27.96 \pm 15.91$ & NS \\
\hline
\end{tabular}

The number in the parentheses is the number of subject detected corresponding steroid.

${ }^{a}$ Concentrations are expressed as $\mathrm{ng} / \mathrm{g}$ of creatinine (mean $\pm \mathrm{SD}$ ).

${ }^{\mathrm{b}} \mathrm{NS}$, not significant.

${ }^{\mathrm{C}} \mathrm{ND}$, not detected.

${ }^{\mathrm{d}} \mathrm{NC}$, not comparable.

its level was lower in PTC men $(P<0.00007)$. Two hydroxylated estrogens at $\mathrm{C}-2$ showed different biological actions between genders. Corticoids were slightly higher in the PTC men and post-menopausal PTC women but not in pre-menopausal PTC women. Progestins were also higher in the patients except for postmenopausal PTC women. In this study, no sterols were shown to be significant in the PTC groups.

\section{Group differences in the steroid metabolism}

To exclude the nature of menopause and gender differences between the patient groups studied, all steroid levels in the PTC groups were normalized to the mean values of the corresponding controls, and the different pathogenesis of PTC was then compared according to the menopausal and gender conditions. Statistical analysis was performed using PLS-DA with normalized levels 
of steroids in the three groups (Additional file. 1). Using the visual inspecting metabolic patterns of steroids and the coincidences between $R^{2} Y$ and $Q^{2} Y$, the pre- and post-menopausal women, and male groups with PTC were clustered individually (Additional file 1A). Their metabolic patterns were discriminated clearly $\left(R^{2} Y=\right.$ 0.727, $Q^{2} Y=0.558$ ). The loading plot of PLS-DA, which is complement to the score plot due to the transposed matrix calculation, was also performed to identify the possible urinary biomarkers. Each data point represents one particular steroid with the relationship between the different PTC patients (Additional file 1B). The metabolic differentiation between the groups complemented the results listed in Additional file 2.

Several possible biomarkers for individual PTC groups were selected (Additional file 2). The levels of androstenediol $(P<0.005)$ was significantly higher in the PTC men than in both PTC women groups, whereas $16 \alpha$ hydroxy DHEA was higher in both pre-menopausal and men with PTC $(P<0.002)$. The normalized androgens levels in PTC men were significantly higher than normalized pre- or post-menopausal PTC women (androstenediol, $P<0.005 ; 16 \alpha$-hydroxy-DHEA, $P<0.002$ ) (Additional file 2). In both PTC women groups, corticosterone $(P<0.005)$ and dihydrodeoxycorticosterone $(P<0.009)$ were higher in the post-menopausal PTC women group than in the pre-menopausal PTC women and PTC men, whereas the post-menopausal PTC women showed lower levels of 11-deoxycorticosterone $(P<0.003)$. The normalized corticoids levels (corticosterone, $P<0.005$; dihydrodeoxycorticosterone, $P<$ 0.009; 11-deoxycorticosterone, $P<0.003$ ) of post-menopausal PTC women were significantly higher than in the other groups (Additional file 2). In progestins, only epipregnanolone showed a significance in post-menopausal PTC women compared to both pre-menopausal and men with PTC $(P<0.0004)$. In the case of 24S-hydroxycholesterol, its urinary concentrations were not remarkable in any of the groups compared, but the normalized values were significantly higher in the pre-menopausal PTC women $(P<0.000002)$. Estrogens (estrone, $P<$ 0.0001 , 2-hydroxy-17 $\beta$-estradiol, $P<0.002$; 4-hydroxyestrone, $P<0.001$; 4-hydroxy-17 $\beta$-estradiol, $P<0.006$; 17 epiestriol, $P<0.0008$ ) in the pre-menopausal PTC women were significantly higher than those of postmenopausal women and men with PTC, whereas 2hydroxyestrone was significantly higher in PTC men $(P$ $<0.0000001)$.

To demonstrate the enzyme activities in the steroid metabolism, the ratio of the steroid metabolite to precursor was examined. Box plots of the altered steroids normalized in all PTC patients showed differences in these ratios (Figure 1). The 16 $\alpha$-hydroxylation of DHEA was differentiated between pre-menopausal women and men with PTC (Figure 1A). In the case of 2-hydroxylation, all PTC groups were significantly discriminated with the 2-hydroxyestrone to estrone ratio (Figure 1B), whereas the 2 -hydroxy-17 $\beta$-estradiol to $17 \beta$-estradiol ratio could differentiate the pre-menopausal PTC women with post-menopausal PTC women and PTC men (Figure 1C). For 2-methoxylation, all groups were differentiated with the ratio of 2-methoxyestrone to 2hydroxyestrone (Figure 1D), whereas $17 \beta$-estradiol represented the pre-menopausal women and men with PTC groups (Figure 1E). 4-methoxylation with the 4methoxyestrone to 4-hydroxyestrone ratio showed differences between post-menopausal PTC women and the other two PTC groups (Figure 1F), whereas 4-hydroxy$17 \beta$-estradiol differentiated between pre-menopausal women and men with PTC (Figure 1G). There were statistically significant differences found in the estrogen metabolites ratio of 2-hydroxyestrone to 2-hydroxy-17 $\beta$ estradiol, which could indicate $17 \beta$-hydroxysteroid dehydrogenase $(17 \beta-\mathrm{HSD})$ between women and men with PTC $\left(<4 \times 10^{-7}\right.$; Figure 2$)$.

\section{Discussion}

Although an understanding of the pathogenesis and development in PTC has been investigated, there is no data available on the metabolic alteration of steroids according to gender and menopausal condition. The metabolic profiling of urinary steroids in pre- and postmenopausal women, and men with PTC were achieved. Due to gender and menopausal variations in steroid biosynthesis, each patient group was normalized to the corresponding control group before comparing the patient groups.

$\mathrm{ER} \alpha$ causes cell proliferation and progress in PTC $[7,12,19]$. The level of ER $\alpha$ is higher in PTC cells than normal cells, and is higher in pre-menopausal women than in both post-menopausal women and men with PTC [7]. The urinary levels of estrogens in pre-menopausal women were investigated first. The concentrations of all estrogens in the pre-menopausal PTC women were higher than the controls, except for 2hydroxyestrone, which was significantly lower (Table 1). The extent to which the 2-hydroxyestrogens are active or can form active or genotoxic metabolites is controversial $[20,21]$. 2-hydroxyestrone has been characterized as the "good estrogen" [22]. In addition, the normalized levels of estrone, 2-hydroxy-17 $\beta$-estradiol, 4-hydroxyestrone, and 4-hydroxy-17 $\beta$-estradiol were also significantly higher in pre-menopausal PTC women than normalized post-menopausal women and men with PTC, whereas the level of 2-hydroxyestrone was significantly up-regulated in PTC men (Additional file 2). In addition, the estrogen metabolism has been shown to potentiate the growth of hormone related cancers, such 

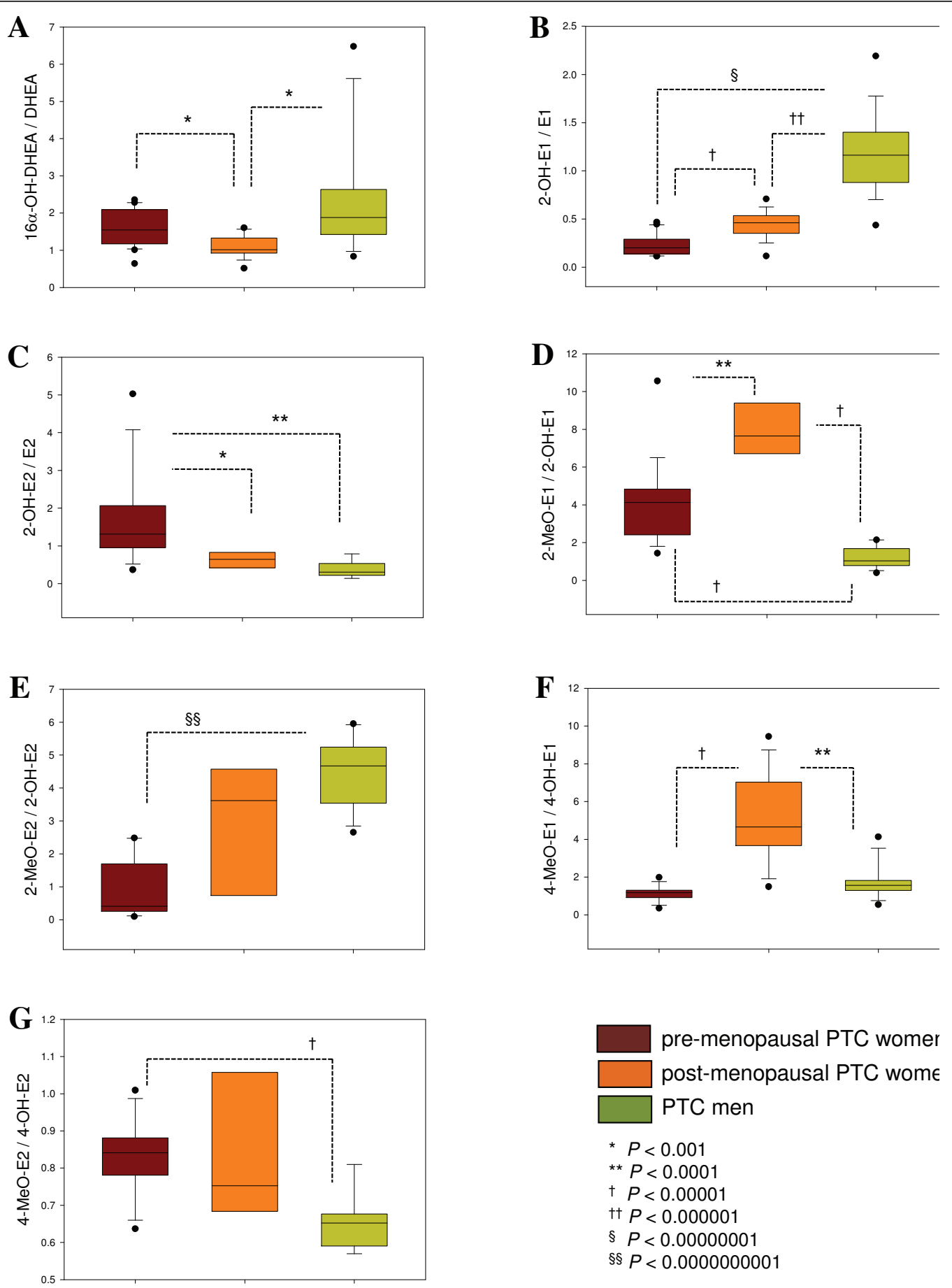

Figure 1 Enzyme activities based on the normalized levels of urinary steroids from pre- and post-menopausal women and men with PTC. The level differences significant at the $P<0.01$ were selected. Line within the box represents the median, lower boundary of the box indicates $25 \%$, and the upper boundary of the box indicates $75 \%$. Whiskers above and below indicate the maximum and minimum steroid levels. Dots above and below indicate the plot outliers with the $10^{\text {th }}$ and $90^{\text {th }}$ percentiles. 


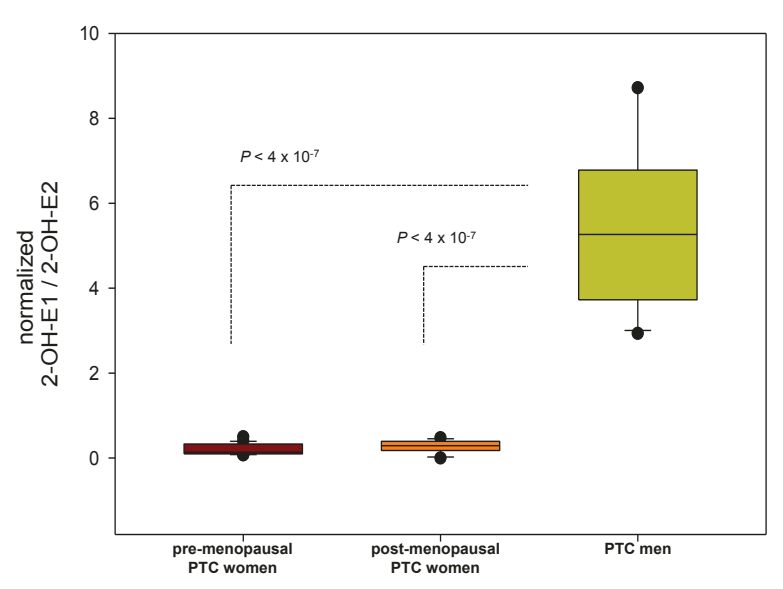

Figure 2 Altered 2-hydroxyestrone to 2-hydroxy-17ß-estradiol metabolic ratio in sex difference. Its metabolic ratio could reveal $17 \beta$-hydroxysteroid dehydrogenase in the estrogen metabolism. Line within the box represents the median, lower boundary of the box indicates 25\%, and the upper boundary of the box indicates $75 \%$. Whiskers above and below indicate the maximum and minimum steroid levels. Dots above and below indicate the plot outliers with the $10^{\text {th }}$ and $90^{\text {th }}$ percentiles.

as breast and cervical cancer [23,24]. 2-Hydroxyestrone and $16 \alpha$-hydroxyestrone as the oxidative metabolites of estrone have different biological actions with anti-proliferation and proliferative effects, respectively, in hormone related cancers $[24,25]$.

In this study, $16 \alpha$-hydroxyestrone was not exactly quantified because of its co-elution with 16-keto-17 $\beta$ estradiol during chromatographic separation. In addition, 4-hydroxyestrone generates reactive oxygen species (ROS) as a source of oxidative stress through estrogen metabolic redox cycling [26] and increases the formation of endogenous carcinogens [24]. Here, 4-hydroxyestrogens was increased significantly, whereas 2-hydroxyestrone was decreased in both PTC women groups (Tables 1, 2 and 3). In general, 2-hydroxyestrone does not have estrogenic activity peripherally and may be anti-estrogenic, leading to an anti-proliferative effect on estrogen-sensitive cells as the good estrogen [27].

AR causes cell proliferation in PTC [15] and its activity is higher in men than women, and is more active in PTC cells than normal cells [14-16]. Nevertheless, the concentrations of most estrogens, except for 2-hydroxy-17 $\beta$ estradiol, and androgens (androstenedione, androstenediol, androsterone, etiocholanolone, and 16 $\alpha$-hydroxyDHEA) in PTC men were higher than the controls (Table 3). The normalized levels of androstenediol and $16 \alpha$-hydroxy-DHEA in PTC men were significantly higher than normalized pre- or post-menopausal PTC women through the higher androgen levels in men (Additional file 2). In addition, the levels of AR were increased by a testosterone treatment in PTC [28]. In this study, the normalized levels of testosterone in PTC men were more significant than pre- or post-menopausal PTC women through AR activation, and the normalized levels of androstenedione and androstenediol as a precursor of testosterone in PTC males were more significant than in the other PTC groups (Additional file 2).

Based on their metabolic actions, corticoids are divided by glucocorticoids and mineralocorticoids, [29] and they are generally considered to simulate lipogenesis, and accelerate fatty acid synthesis [30,31]. Therefore, the concentrations of both corticoids series, such as corticosterone, dihydrodeoxycorticosterone, tetrahydrocortisol, and tetrahydrocorticosterone in post-menopausal PTC women are higher than its controls (Table 2). However, the normalized levels of mineralocorticoids including corticosterone, dihydrodeoxycorticosterone, and 11-deoxycorticosterone in post-menopausal PTC women were significantly higher than in the other groups (Additional file 2).

Many steroids and metabolic ratios indicate both menopausal and gender differences in PTC progression (Figure 1) but their levels are discriminated by the degree of up-regulation in PTC patients. In particular, 2 -hydroxyestrone and 2-hydroxy-17 $\beta$-estradiol show reversible actions between pre-menopausal women and men with PTC (Tables 1 and 3). 2-hydroxyestrone stimulates the anti-proliferation of cancer cells directly, whereas the effect of 2-hydroxy-17 $\beta$-estradiol on carcinomas is more complex. In addition, 2 -hydroxy-17 $\beta$ estradiol was up-regulated in the pre-menopausal PTC women and its production may result in oxidative DNA damage and apoptosis in human mammalian cells [32]. Inter-conversion between 2-hydroxyestrone and 2hydroxy-17 $\beta$-estradiol catalyzed by $17 \beta-$ HSD was significantly altered in PTC men against both pre- and postmenopausal women with PTC (Figure 2). The expression of $17 \beta-\mathrm{HSD}$ is not only specific in thyroid disorders [7], but may indicate the gender differences. However, its reversible actions in men have not been investigated.

\section{Conclusions}

Although both most androgens and estrogens were increased in the pre-menopausal women with PTC in this study, hydroxylation and methoxylation with estrogens explained more the metabolic changes between all groups studied. In this cross-sectional study, the thyroid cancer risk might be associated with lower 2-hydroxyation activities of either estrone or $17 \beta$-estradiol in women and men. Overall, the 2-hydroxyestrone to 2hydroxy-17 $\beta$-estradiol metabolic ratio, which indicates the activity of $17 \beta-$ HSD, may in fact be gender differences in the thyroid cancer progression. These results may help better understand the pathogenesis of PTC according to gender and menopausal conditions. 


\section{Additional material}

Additional file 1: PLS-DA score (A) and loading (B) plots from a profiling of $\mathbf{8 4}$ urinary steroids. The steroid profiling of pre- and postmenopausal female, and male patients with papillary thyroid carcinoma (PTC) was conducted. The levels of urinary steroids were normalized to the mean values of individual control groups and then differentiated by one-way ANOVA. The abbreviation of the steroids in the loading plot was obtained from reference 20 .

Additional file 2: Levels of normalized urinary steroids in the preand post-menopausal women and men with PTC. To exclude the nature of menopause and gender differences between the patient groups studied, all steroid levels in the PTC groups were normalized to the mean values of the corresponding controls, and the normalized differentiation proposed several possible biomarkers.

\section{Acknowledgements}

This study was supported by an intramural grant from the Korean Institute of Science and Technology, and by the Converging Research Center Program through the Ministry of Education, Science and Technology (2010K001117).

\section{Author details}

${ }^{1}$ Future Convergence Research Division, Korea Institute of Science and Technology, Seoul 136-791, Korea. ${ }^{2}$ Department of Internal Medicine, Yonsei University College of Medicine, Seoul 120-752, Korea.

\section{Authors' contributions}

$\mathrm{MHC}$ carried out the preparing manuscript and the experimental design. JYM developed the analytical assay and performed the statistical analysis. SHC participated in the design of the study and carried out the steroid profiling. BCC conceived of the study, and participated in its design and coordination and helped to draft the manuscript. EJL participated in preparing the experimental protocol, clinical diagnosis and sampling. All authors revised the manuscript and approved the final version.

\section{Competing interests}

The authors declare that they have no competing interests.

Received: 7 March 2011 Accepted: 8 August 2011

Published: 8 August 2011

\section{References}

1. Correa P, Chen WW: Endocrine gland cancer. Cancer 1995, 75:338-352.

2. Rosenthal DS: Changing trends. CA Cancer J Clin 1998, 48:3-23.

3. Manole D, Schildknecht B, Gosnell B, Adams E, Derwahl M: Estrogen promotes growth of human thyroid tumor cells by different molecular mechanisms. J Clin Endocrinol Metab 2001, 86:1072-1077.

4. Sakoda LC, Horn-Ross PL: Reproductive and menstrual history and papillary thyroid cancer risk: the San Francisco Bay area thyroid cancer study. Cancer Epidemiol Biomarks Prev 2002, 11:51-57.

5. Levi F, Franceschi S, Gulie C, Negri E, La Vecchia C: Female thyroid cancer: the roles of reproductive and hormonal factors in Switzerland. Oncology 1993, 50:309-315.

6. Diaz NW, Mazoujian G, Wick MR: Estrogen-receptor protein in thyroid neoplasms: an immunohistochemical analysis of papillary carcinoma, follicular carcinoma, and follicular adenoma. Arch Pathol Lab Med 1991, 115:1203-1207.

7. Kawabata W, Suzuki T, Moriya T, Fujimori K, Nagamura H, Inoue S, Kinouchi Y, Kameyama K, Takami H, Shimosegawa T, Sasano H: Estrogen receptors ( $\alpha$ and $\beta$ ) and 17 $\beta$-hydroxysteroid dehydrogenase type 1 and 2 in thyroid disorder: possible in situ estrogen synthesis and actions. Mod Pathol 2003, 16:437-444.

8. Mori M, Naito M, Watanabe H, Takeichi N, Dohi K, Ito A: Effects of sex difference, gonadectomy and estrogen on $\mathrm{N}$-methyl- $\mathrm{N}$-nitrosourea induced rat thyroid tumors. Cancer Res 1990, 50:7662-7667.

9. Negri E, Dal Maso L, Ron E, La Vecchia C, Mark SD, Preston-Martin S, McTiernan A, Kolonel L, Yoshimoto Y, Jin F, Wingren G, Rosaria Galanti M,
Hardell L, Glattre E, Lund E, Levi F, Linos D, Braga C, Franceschi S: A pooled analysis of case-control studies of tyroid cancer II. Menstrual and reproductive factors. Cancer Causes Control 1999, 10:143-155.

10. La Vecchia C, Ron E, Franceschi S, Dal Maso L, Mark SD, Chatenoud L, Braga C, Preston-Martin S, McTiernan A, Kolonel L, Mabuchi K, Jin F, Wingren G, Galanti MR, Hallquist A, Lund E, Leve F, Linos D, Negri E: A pooled analysis of case-control studies of tyroid cancer III. Oral contraceptives, menopausal replacement therapy and other female hormones. Cancer Causes Control 1999, 10:157-166.

11. Segey DL, Umbricht C, Zeiger MA: Molecular pathogenesis of thyroid cancer. Surg Oncol 2003, 12:69-90.

12. Zeng Q, Chen GG, Vlantis AC, Tse GM, Hasselt CA: The contributions of oestrogen receptor isoforms to the development of papillary and anaplastic thyroid carcinomas. J Pathol 2008, 214:425-433.

13. Prinz RA, Sandberg L, Chaudhuri PK: Androgen receptors in human thyroid tissue. Surgery 1984, 96:996-1000.

14. Rossi R, Franceschetti P, Maestri I, Magri E, Cavazzini L, degli Uberti EC, del Senno $L$ : Evidence for androgen receptor gene expression in human thyroid cells and tumours. J Endocrinol 1996, 148:77-85.

15. Marugo M, Torre G, Bernasconi D, Fazzuoli L, Cassulo S, Giordano G: Androgen receptors in normal and pathological thyroids. J Endocrinol Invest 1991, 14:31-35.

16. Miki H, Oshimo K, Inoue $H$, Morimoto T, Monden Y: Sex hormone receptors in human thyroid tissues. Cancer 1990, 66:1759-1762.

17. Moon JY, Jung HJ, Moon MH, Chung BC, Choi MH: Heat-map visualization of gas chromatography-mass spectrometry based quantitative signatures on steroid metabolism. J Am Soc Mass Spectrom 2009, 20:1626-1637.

18. Husdan H, Rapoport A: Estimation of creatinine by the Jaffe reaction. A comparison of three methods. Clin Chem 1968, 14:222-238.

19. Zeng $\mathrm{Q}$, Chen $\mathrm{GG}$, Vlantis $\mathrm{AC}$, Hasselt CA: Oestrogen mediates the growth of human thyroid carcinoma cells via an oestrogen receptor - ERK pathway. Cell Prolif 2007, 40:921-935.

20. Martucci C, Fishman J: Direction of estradiol metabolism as a control of its hormonal action-uterotrophic activity of estradiol metabolites. Endocrinology 1977, 101:1709-1715.

21. Liehr JG, Ulubelen AA, Strobel HW: Cytochrome P-450 mediated redox cycling of estrogens. J Biol Chem 1986, 261:16865-16870.

22. Bradlow HL, Telang NT, Sepkovic DW, Osborne MP: 2-Hydroxyestrone: the "good" estrogen. J Endocrinol 1996, 150:S259-S265.

23. Miller DG, Sepkovic DW, Bradlow HL, Martucci CP, Levine BS, CunninghamRundles $S$ : The effect of nutritional intervention on immune functions and other biomarkers in high cancer risk individuals. J Nutri Immunol 1997, 5:9-15.

24. Parl FF, Dawling S, Roodi N, Crooke PS: Estrogen metabolism and breast cancer: a risk model. Ann N Y Acad Sci 2009, 1155:68-75.

25. Chan EK, Sepkovic DW, Yoo Bowne HJ, Pei Yu G, Schantz SP: A hormonal association between estrogen metabolism and proliferative thyroid disease. Otolaryngol Head Neck Surg 2006, 134:893-900.

26. Roy D, Liehr JG: Estrogen, DNA damage and mutations. Mutat Res 1999, 424:107-115.

27. Swaneck G, Fisman J: Covalent binding of the endogenous estrogen 16hydroxyestrone to estradiol receptors in human breast cancer cells: characterization and intranuclear localization. Proc Natl Acad Sci USA 1988, 85:7831-7835.

28. Banu SK, Govindarajulu P, Aruldhas MM: Testosterone and estradiol upregulate androgen and estrogen receptors in immature and adult rat thyroid glands in vivo. Steroids 2002, 67:1007-1014.

29. Cho HJ, Kim JD, Lee W-Y, Chung BC, Choi MH: Quantitative metabolic profiling of 21 endogenous corticosteroids in urine by liquid chromatography-triple quadrupole-mass spectrometry. Anal Chim Acta 2009, 632:101-108

30. Hillgartner FB, Salati LM, Goodridge AG: Physiological and molecular mechanisms involved in nutritional regulation of fatty acid synthesis. Physiol Rev 1995, 75:47-76.

31. Berdanier CD: Role of glucocorticoids in the regulation of lipogenesis. FASEB J 1989, 3:2179-2183.

32. Hurh YJ, Chen ZH, Na HK, Han SY, Suhr YJ: 2-Hydroxyestradiol induces oxidative DNA damage and apoptosis in human mammary epithelial cells. J Toxicol Environ Health A 2004, 67:1939-1953. 


\section{Pre-publication history}

The pre-publication history for this paper can be accessed here:

http://www.biomedcentral.com/1471-2407/11/342/prepub

doi:10.1186/1471-2407-11-342

Cite this article as: Choi et al: Metabolic alteration of urinary steroids in

pre- and post-menopausal women, and men with papillary thyroid

carcinoma. BMC Cancer 2011 11:342.

Submit your next manuscript to BioMed Central and take full advantage of:

- Convenient online submission

- Thorough peer review

- No space constraints or color figure charges

- Immediate publication on acceptance

- Inclusion in PubMed, CAS, Scopus and Google Scholar

- Research which is freely available for redistribution

Submit your manuscript at 